\title{
O processo de Cartagena de 1984 e os fluxos migratórios venezuelanos.
}

The 1984 Cartagena process and venezuelan migratory flows.

Resumo: Com o objetivo de verificar a pertinência do chamado Processo de Cartagena de 1984 aos fluxos migratórios advindos da Venezuela e de identificar as diretrizes da proteção internacional dos refugiados no referido país, foi realizado uma investigação a partir de pesquisa bibliográfica e análise documental. Considerando que a Declaração de Cartagena de 1984 traz o significado mais abrangente para a definição de refugiado, faz-se de extrema relevância analisar a incidência de sua aplicação no caso venezuelano. Neste trabalho, buscou-se perquirir a aplicação da Declaração de Cartagena à situação da Venezuela, analisando a sua política migratória e a incidência normativa deste processo. Concluiu-se que a crise humanitária venezuelana gera um deslocamento internacional misto, a qual, uma vez identificada pelos países de acolhida, deve ensejar uma imediata e ampla proteção para além das soluções individuais, baseadas em soluções duradouras previstas desde o Plano de Ação do México de 2004.

Palavras-chave: Declaração de Cartagena de 1984. Fluxos Migratórios Venezuelanos. Soluções Duradouras

\begin{abstract}
In order to verify the relevance of the 1984 Cartagena Process to the migratory flows from Venezuela and to identify the guidelines for the international protection of refugees in that country, an investigation was carried out based on bibliographic research and documentary analysis. Considering that the 1984 Cartagena Declaration brings the most comprehensive meaning to the definition of a refugee, it is extremely important to analyze the incidence of its application in the Venezuelan case. In this work, we sought to investigate the

\footnotetext{
* Doutor em Ciência Política pela Universidade Federal do Rio Grande do Sul. Possui a Certificação Acadêmica do Instituto Interamericano de Direitos Humanos de San Jose da Costa Rica, responsável pela implantação da Cátedra Sergio Vieira de Mello na Universidade Federal da Grande Dourados (UFGD). Atualmente é professor adjunto da Faculdade de Direito (FADIR) da Universidade Federal do Mato Grosso do Sul (UFMS), em Campo Grande, e professor do Mestrado Interdisciplinar Fronteiras e Direitos Humanos da Faculdade de Direito e Relações
} Internacionais da UFGD, em Dourados-MS.
\end{abstract}


Revista Brasileira de História \& Ciências Sociais - RBHCS

Vol. 13 No 26, Janeiro - Junho de 2021

application of the Cartagena Declaration to the situation in Venezuela, analyzing its migration policy and the normative impact of this process. It was concluded that the Venezuelan humanitarian crisis generates a mixed international displacement, which, once identified by the host countries, must provide immediate and comprehensive protection in addition to individual solutions, based on durable solutions provided for in the Mexico Plan of Action of 2004.

Keywords: Cartagena Declaration of the 1984. Venezuelans Migratory Flows. Lasting Solutions.

\section{INTRODUÇÃO}

Quanto ao desenvolvimento do denominado Direito Internacional dos Refugiados, estabeleceu-se a Convenção Relativa ao Estatuto dos Refugiados de 1951, da Organização das Nações Unidas (ONU), como marco inicial do nascimento da definição clássica de refugiado, embora esta construção remonte ao período da década de 20 do século XX (TORPEY, 2005, p.158-159), já que tal instrumento foi criado para regular os deslocamentos forçados decorrentes da Primeira e da Segunda Guerras Mundiais.

A próxima etapa ocorre por meio de uma evolução conceitual, com o Protocolo Adicional ao Estatuto dos Refugiados de 1967, com o objetivo de adaptar à nova realidade mundial pós descolonização africana e asiática, e não apenas como produtos de guerras mundiais anteriores.

E tendo em vista as graves e generalizadas violações de direitos humanos que apareciam como padrão e em grande quantidade em várias regiões do mundo, enquanto consequência deste processo de descolonização, como guerras civis e conflitos intermitentes, derivados do clima de Guerra Fria (ZOLBERG, SUHRKE, AGUAYO, 1989, p. 180).

A Declaração de Cartagena de 1984 vem, assim, configurar um conceito de refugiado e iniciar um sistema mais amplo de proteção especificamente voltado para a região das Américas, o chamado processo de Cartagena, inspirado na Convenção da Organização da Unidade Africana, de 1969 (JARDIM, 2017, p.164). O conceito ampliado objetivou adequar a definição ao que acontecia na América Latina enquanto graves e generalizadas violações de 
Revista Brasileira de História \& Ciências Sociais - RBHCS

Vol. 13 No 26, Janeiro - Junho de 2021

direitos humanos, conectando diretamente o Direito dos Refugiados ao Direito Internacional dos Direitos Humanos (LINDGREN ALVES, 2018, p.275).

A Declaração de Cartagena apareceu enquanto uma espécie de resposta normativa para a efetivação de outros direitos e de modo a lidar com o clima de Guerra Fria e as ditaduras militares, que produziam enorme quantidade de refugiados reconhecidos pelo ACNUR (Alto Comissariado das Nações Unidas para Refugiados). É importante frisar que com a ampliação do conceito global da ONU, mais pessoas podiam ser protegidas diante desta realidade latinoamericana, de modo a demonstrar assim um determinado grau de desenvolvimento desde a Convenção de Genebra até a Declaração de Cartagena (TRINDADE, 1997, p. 328-338).

O documento de Cartagena foi apenas um primeiro passo iniciado com a Declaração de 1984, e que passaria ainda pela Declaração de San José de 1994 sobre Refugiados e Pessoas Deslocadas, assim como pela Declaração do México de 2004. Este último documento regional não apenas validou importantes princípios de proteção advindos das normativas anteriores como criou o chamado primeiro Plano de Ação regional, introduzindo programas de inovação solidárias aos quais deviam promover soluções duradouras para quem necessitava de proteção internacional (ACNUR, 2015, p. 14). Tal iniciativa parecia prever o fenômeno do deslocamento maciço de venezuelanos e outros países da América Central que ocorreria logo na década seguinte.

A produção de novos documentos normativos de modo a confirmar a Declaração de Cartagena teve ainda continuidade com a Declaração e o Programa de Ação do Brasil, estabelecido em dezembro de 2014, com a adoção de novas estratégias para responder aos desafios impostos pelo deslocamento forçado na região pelas próximas décadas (ACNUR, 2015, p. 15).

A América Latina contribuiu muito com o desenvolvimento progressivo na construção normativa da proteção internacional dos direitos humanos dos refugiados, com a Declaração Americana dos Direitos e Deveres do Homem de 1948, a Convenção Americana sobre Direitos Humanos de 1969, a mencionada de Declaração de Cartagena sobre os Refugiados de 1984, e os outros documentos regionais produzido a cada dez anos para confirmar o espírito de Cartagena, no contexto do sistema interamericano de direitos humanos. 
O trabalho presente busca verificar a incidência de todo este processo de produção de documentos normativos regionais, conhecidos como Processo de Cartagena de 1984 aos fluxos migratórios recente advindos da Venezuela e de identificar as diretrizes da proteção regional dos refugiados aplicáveis ao país.

$\mathrm{Ou}$ seja, a pesquisa busca investigar a aplicação das iniciativas de Cartagena à situação da Venezuela, de modo a vislumbrar particularmente as soluções duradouras cabíveis ao caso venezuelano, uma população majoritariamente em processo de diáspora, desde que os problemas daquele país eclodiram de maneira mais incisiva na segunda metade da década passada, produzindo milhares de pessoas deslocadas e em situação de refúgio.

\section{OS FLUXOS MIGRATÓRIOS RECENTES E A QUESTÃo VENEZUELANA}

Assim, surgiu o problema recente da República Bolivariana da Venezuela que, apesar de na atualidade registrar um dos maiores deslocamentos de refugiados no planeta, possui um rico histórico de acolhimento de refugiados desde a Segunda Guerra Mundial, oportunidade em que foi o segundo país que mais acolheu os deslocados forçados provenientes daquele conflito mundial. (SILVA, 2020).

Além disso, quando, juntamente com a criação do ACNUR, foi instituído o Comitê Consultivo para Refugiados e o Comitê Executivo no âmbito da ONU, ambos órgãos voltados a monitorar a situação de refúgio no mundo, a Venezuela foi mais uma vez considerado pelo ACNUR como país que demonstrava interesse em solucionar a questão dos refugiados, e juntamente com o Brasil, foi convidada, como representante latino-americano a acompanhar os procedimentos técnicos.

Dentre os fluxos migratórios presentes nas Américas, o mais significativo em direção à Venezuela nos últimos anos foi o de colombianos, principalmente na área limítrofe entre fronteiras, onde, alcançando os estados venezuelanos de Táchira, Zulia, Apure e Amazonas, se instalaram grupos de guerrilheiros e narcotraficantes, resultando, assim, em altas taxas de deslocamentos forçados por causas combinadas, como violência generalizada e massacres coletivos. Contudo, os deslocamentos mais significativos são 
originários principalmente dos estados colombianos de La Guajira, devido à pobreza, o norte de Santander devido à presença de minas terrestres; e em Arauca, por conflitos entre as forças dos grupos armados não-estatais FARC e ELN e o exército colombiano (MALAVER, 2012, p. 17-18).

Sendo assim, procurou-se executar uma série de medidas por parte do governo venezuelano em parceria com o ACNUR, a fim de tentar mitigar os problemas provenientes deste fluxo migratório. Ou seja, a adoção de associações para ajuda financeira aos refugiados, a organização de um sistema de registro a fim de contabilizar e obter informações sobre as necessidades dessas pessoas e as características singulares de seu deslocamento, além de programas na direção de se facilitar os procedimentos de refúgio, da conscientização e de ampla informação nas comunidades mais afastadas, além da capacitação dos profissionais que atuam nas fronteiras (SILVA, 2020, p.81). Fora isso, ações direcionadas especificamente às comunidades indígenas que vivem na região fronteiriça, as quais necessitariam de proteção especial diante de suas múltiplas vulnerabilidades, especialmente os índios waraos (ZANONI, 2019, p. 135).

Apesar de seu histórico aparentemente acolhedor nos debates da arena internacional sobre a temática, os termos da legislação venezuelana em vigência para a situação de refúgio, encontram-se claramente ultrapassados. A Constituição venezuelana, promulgada em 1999, garante o direito ao refúgio na lista de direitos políticos e em suas disposições transitórias prevê a criação de uma lei orgânica para a regulamentação do instituto.

A lei, chamada de Ley Orgánica Sobre Refugiados O Refugiadas y Asilados o Asiladas (LORRAA), $n \cdot{ }^{\circ} 37.296$, foi criada em 2001 e regulamentada pelo Decreto 2.491/03, levando em consideração somente a definição trazida pela Convenção de Genebra de 1951 relativa ao Estatuto dos Refugiados, ratificado pela Venezuela em 19861', não considerando, assim, a Declaração de Cartagena de 1984, e determina que:

Artículo 4. Condición de refugiado o refugiada. El Estado venezolano considerará como refugiado o refugiada a toda persona a quien la autoridad competente le reconozca tal condición, en virtud de haber ingresado al territorio nacional debido a fundados temores de ser perseguida por motivos de raza, sexo, religión, nacionalidad, pertenencia a determinado

1 ACNUR. ¿Quién es un refugiado? Disponível em: https://help.unhcr.org/venezuela/solicitando-la-condicion-de-refugiado/quien-es-unrefugiado/ Acesso em: 10/07/ 2020. 
Revista Brasileira de História \& Ciências Sociais - RBHCS

Vol. 13 No 26, Janeiro - Junho de 2021

grupo social u opinión política, y se encuentre fuera del país de su nacionalidad y no pueda o no quiera acogerse a la protección de tal país

Mesmo que a Venezuela tenha participado do processo de consolidação dos princípios consagrados no documento regional, o país não o encorajou, tendo em vista a sua natureza opcional e não vinculante, motivo pelo qual sua legislação não contém qualquer menção à ampliação da definição estabelecida em Cartagena 1984.

Neste mesmo período, enquanto estava sendo produzida a referida lei e aconteciam os primeiros casos de deslocamento maciço de colombianos para a Venezuela, aplicou-se uma política restritiva diante das solicitações de refúgio, inclusive com deportação de pessoas (SILVA, 2020, p. 70). Tais deslocamentos forçados não iriam diminuir até 2014, quando a lógica se inverteu, e a Venezuela acabou tornando-se um país produtor de refugiados, devido sobretudo ao auge da crise de sua produção petrolífera combinado com decisões políticas e sociais drásticas e equivocadas.

A citada lei orgânica também garante à vítima de deslocamento forçado uma lista de instrumentos de proteção, instrumentos que na teoria seriam utilizadas para a proteção dos direitos humanos de refugiados e de apátridas que recorram a tal instância internacional protetiva. Estas diretrizes seriam os princípios gerais de direito internacional dos refugiados: da não-devolução, o da não criminalização da migração, o da reunificação familiar, além do interesse superior da criança.

Quanto às interpretações possíveis, a lei ainda sublinha a interpretação pro homine quando estabelece que em caso de dúvida, será aplicada a norma mais favorável ao exercício dos direitos do solicitante de refúgio ou de asilo. É importante ainda frisar a importância da "Comisión Nacional para los Refugiados", o órgão responsável por orientar e coordenar as ações necessárias à proteção, assistência e apoio jurídico para os solicitantes de refúgio e refugiados. Além de decidir os casos referentes à determinação da condição de refugiado, bem como a sua cessação e perda da condição e a expulsão (SILVA, 2020).

Um aspecto importante desta Comissão é a possibilidade de um representante do ACNUR participar de suas sessões, bem como assessorar os solicitantes de refúgio e os refugiados, entretanto apenas com direito à voz e não 
a voto (tal como a experiência brasileira). Mas o procedimento deve durar até noventa dias, devendo ser o escritório do ACNUR na Venezuela notificado sobre a negativa, a qual deverá ser fundamentada. Com a decisão favorável, a Comissão notifica o Ministério do Interior e da Justiça para a emissão do documento de identidade.

Quando do reconhecimento da condição de refugiado, as pessoas admitidas na Venezuela precisam obedecer a Constituição, e de nenhuma forma interferir nos assuntos políticos que fossem contra a segurança nacional ou interesses políticos da Venezuela. O que claramente evidencia um foco no poder do Estado, e não no reconhecimento internacional da condição de refugiado enquanto proteção. No caso da expulsão do território, que também deverá ser fundamentada por atos contra a ordem pública e a segurança nacional, esta deverá ser também comunicada ao escritório do ACNUR.

Apesar da aparente proteção normativa, a legislação demonstra-se eivada de vagueza com um certo grau de dubiedade nos procedimentos posteriores, visto que há notáveis diferenças entre a lei e o decreto que a regulamenta, como nos casos de asilo político, previsto, mas não regulamentado nem citado no decreto, e também nas hipóteses de fluxos migratórios maciços, sobre as quais há um capítulo especialmente destinado ao tema, definidas e divididas entre pessoas que irão utilizar o território venezuelano enquanto passagem temporária; e aqueles que irão solicitar refúgio.

Contudo, no decreto, em compensação, só é regulamentada a possibilidade de permanecer temporariamente durante o prazo de noventa dias, podendo ser renovada a autorização por mais noventa dias. Fora disso não há regulamentação do refúgio, motivo que representa uma espécie de restrição para esse grupo de pessoas conseguir regularizar sua situação migratória. Ou seja, configurando uma realidade venezuelana de um pequeno número de pessoas registradas como refugiadas e um grande número de pessoas vivendo em condição análoga, mas que não farão parte das estatísticas oficiais. (SILVA, 2020, p. 82)

Outra questão fundamental deriva do fato do país historicamente receber fluxos maiores de refugiados do que outros países, e comparativamente possuir uma regulamentação menos protetiva e em certo grau bastante restritiva. Isso pode demonstrar que países que possuam um fluxo maior de 
refugiados em direção ao seu território busquem construir sua legislação de forma mais restritiva no que tange à proteção desse contingente, como também ocorre no Panamá (MENEZES, 2011, p.105-107). Em ambos os casos, uma medida que busca ser emergencial, no caso de fluxos maciços, no longo prazo acaba por impedir que se reconheça a condição de refugiado e o amparo protetivo que provém de tal medida:
A Venezuela (Decreto $\mathrm{n}^{\circ}$ 2.491/2003) e o Panamá (Decreto Executivo n. ${ }^{0}$ 23/1998), por exemplo, confirmam a tese de SUHRKE (1998, p. 398), de que uma resposta individual para um problema regional pode significar menos proteção. Esses dois países criaram em suas legislações internas sobre refugiados um capítulo sobre a proteção temporária, com o objetivo de impedir o acesso, nos casos de fluxo massivo de refugiados, ao procedimento de solicitação de refúgio (MENEZES, 2011).

Ainda que caracterizada como deslocamento forçado produto de migrações de crise, produzida através de decisões políticas e sociais radicais combinadas com acontecimentos econômicos mais amplos, os fluxos venezuelanos nem de longe puderam ser previstos como sendo capaz de gerar uma das maiores crises migratórias da história recente da América Latina. Segundo o relatório Integração Local e Interiorização de Venezuelanos, do ACNUR (2019), as causas para o deslocamento forçado variam e combinam entre ameaças e violências por grupos armados, perseguição política, desabastecimento, combinado com falta de acesso a serviços públicos e recursos básicos, além da inflação.

A dinâmica atual modificou drasticamente os fluxos migratórios regionais, de modo que se a Venezuela era um dos principais países a receber fluxos migratórios oriundos da Colômbia, em virtude de seu desenvolvimento social e econômico de outrora, na atualidade, é a Colômbia que se torna um país de acolhida do deslocamento forçado de milhares de venezuelanos. Ainda que as razões que motivam o abandono do país pelos próprios colombianos não tenham cessado ou diminuído ${ }^{2}$, visto que os debates de paz entre governo colombiano e grupos insurgentes não tem sido exitosa para a população

2 NORWEGIAN REFUGEE COUNCIL. Thousands of people newly displaced in Colombia. Disponível em: https://www.nrc.no/news/2019/april/thousands-of-people-newlydisplaced-in-colombia/ Acesso em: 10 jul. 2020. 
migrante (SAEZ, 2017, p.192-193). Um outro documento, produzido pela delegação do Comitê Internacional da Cruz Vermelha presente no país, confirma que a situação estaria ainda mais complexa do que à época da assinatura dos acordos de paz3.

E conforme a Human Rights Watch, a Colômbia foi o principal país de acolhida escolhido pelos venezuelanos, tanto pela facilidade de atravessar as fronteiras terrestres, que devido à crise generalizada de segurança acaba sendo uma zona turbulenta em termos de monitoramento e fiscalização dos fluxos migratórios para o governo colombiano, quanto pela questão da facilidade do idioma4. Além disso, Colômbia e Venezuela possuem uma fronteira terrestre de cerca de $2.219 \mathrm{~km}$, com sete pontos de controle migratório e um número indeterminado de travessias informais (SILVA, 2020, p. 83).

A escolha dos refugiados venezuelanos de partirem para a Colômbia diante da crescente violência generalizada, especialmente na região fronteiriça do país de destino só poderia se justificar pela profunda inviabilidade de permanecer em seu país de origem, o que evidencia as condições e a vulnerabilidade de sua situação. Nesse sentido, conforme a plataforma Response for Venezuelans (R4V) - a qual fiscaliza os venezuelanos em movimento desde 2016, estes indivíduos na Colômbia ultrapassaram cerca de dois milhões de pessoas, dentre imigrantes, refugiados e solicitantes de refúgio reportados pelo governo colombiano, sem considerar as estatísticas dos não registrados e irregulares.

Quanto ao número total presente em toda a América Latina, os venezuelanos deslocados chegaram ao número de 4,5 milhões, dentre a soma de imigrantes, refugiados e solicitantes de refúgio, reportados por todos os governos da região. Segundo o Relatório Tendências Globais do ACNUR (2019, p. 3-10), é provável que o número venha a crescer cada vez mais nos próximos anos, tendo em vista as pessoas vivendo em condições análogas, e que ainda não foram contadas. Os deslocamentos internacionais mistos e os movimentos secundários parecem sinalizar que as razões para produção de refugiados e

\footnotetext{
3 International Committee of the Red Cross. The humanitarian situation in Colombia worsened during 2018. Disponível em: https://www.icrc.org/en/document/humanitariansituation-colombia-worsened-during- Acesso em: 10/07/ 2020.

4 HUMAN RIGHTS WATCH. Colombia: events of 2o18. World Report 2019. Disponível em: https://www.hrw.org/world-report/2019/country-chapters/colombia Acesso em 10 /07/2020.
} 
Revista Brasileira de História \& Ciências Sociais - RBHCS

Vol. 13 No 26, Janeiro - Junho de 2021

deslocados internos seguem em ascensão, particularmente nas fronteiras dos Estados, sendo a Venezuela um exemplo emblemático.

Para enfrentar os desafios que se apresentavam foi criado em 2016, então, o Grupo Interagências sobre Fluxos Migratórios Mistos (GIFMM), sob coordenação da Organização Mundial das Migrações (OIM) e do ACNUR, o qual busca soluções conjuntas para a situação dos refugiados e migrantes presentes na Colômbia.(SILVA, 2020, p. 85).

Verificando as características do deslocamento forçado de venezuelanos, de modo a verificar suas singularidades, constata-se que as condições em que ocorre este deslocamento são de alta vulnerabilidade social e econômica, pois muitos desses imigrantes e refugiados se encontram com desnutrição e outras doenças como tuberculose, difteria e malária, tendo em vista que a maior parte do contingente migratório se desloca à pé, em bloco, atravessando fronteiras territoriais, enquanto um fenômeno conhecido como "los caminantes" (TORRADO, 2018). Como consequência, apareceram relatos das tentativas dos "coiotes" e de autoridades locais de extorquir o pouco que os venezuelanos trazem consigo para sobreviver.

Além disso, o fluxo migratório de deslocamento forçado de venezuelanos claramente não possui características de uma migração somente econômica, considerando que os fluxos historicamente tendem a se padronizar em estatísticas e no impacto regional quando provém das mesmas dinâmicas (SILVA, 2020). Conforme a Organização dos Estados Americanos (OEA, 2019, p. 19), a crise humanitária venezuelana revela, enquanto efeito colateral, o deslocamento forçado correspondente em números às movimentações maciças causadas por conflitos armados, sendo que a velocidade no crescimento do número total de pessoas deslocadas se configura nos moldes da crise humanitária da Síria em seus primeiros anos, e tão alta quanto:

Segundo, la magnitud y la velocidad del flujo migratorio de venezolanos tiene similitudes con otros episodios que han resultado en crisis masivas de migrantes y refugiados en el mundo, las cuales se han originado por conflictos bélicos tales como en Siria, Afganistán, Somalia y Sudan del Sur. Las características del flujo no son típicas de migraciones puramente económicas.

Em compensação, o financiamento internacional levantado para enfrentar a crise humanitária venezuelana comparado ao montante destinado 
para a crise humanitária na Síria é relativamente pequeno e insuficiente para a questão. Provavelmente, no longo prazo, resultará em um apoio marcadamente impróprio, visto que o prognóstico para os próximos anos é de um aumento do deslocamento forçado, devendo chegar a mais de oito milhões de pessoas, nos próximos anos:

Comparado a la crisis de refugiados sirios, por ejemplo, la cantidad de financiamiento por refugiado está por encima de 5.000 dólares por persona; en el caso venezolano, inclusive con el financiamiento solicitado en el 2019 y el número actual de migrantes y refugiados de 3.4 millones, el monto estaría por debajo de 300 dólares por persona. (OEA, 2019)

Esta evidência demonstra a pouca ou relativa importância que a comunidade internacional olha para esta questão, mesmo diante da magnitude do problema venezuelano, e tal comportamento pode ter sido produzido justamente pelas prioridades colocadas em outros lugares do mundo, com crises humanitárias similares, além da compreensão genérica da urgência da situação, e pelas restrições impostas pelos países quando o assunto é uma crise migratória humanitária, a qual se assemelhariam em grande medida à uma migração econômica, mas que tem-se configurado como uma migração internacional mista, com claros desdobramentos de migração multicausal (GABORIT, 2016, p. 15), e de movimentos secundários.

\section{O Processo de Cartagena de 1984 e a Diáspora Venezuelana}

A ampliação da definição de refugiado encontra seu fundamento na necessidade de proteção do contingente populacional deslocado para além das fronteiras de seu país de origem, pelos mais diversos motivos, considerando que, se por um lado, o deslocamento maciço forçado possui causas variadas e múltiplas, por outro, todas estas convergem para o mesmo resultado: a inviabilidade de permanecer no local de origem, para além dos motivos clássicos colocados na Convenção de Genebra de 1951 (HATHAWAY, FOSTER, 2014, p. 3-10).

Os refugiados, independentemente das causas que produziram sua condição, pertence a uma categoria de pessoas, para com a qual o seu Estado de origem falhou em proteger e em garantir os seus direitos humanos, seja através de ação ou de omissão, perpetrando ou produzindo graves e generalizadas 
violações de direitos humanos. O fluxo migratório de refugiados venezuelanos atual evidencia muito claramente as falhas do sistema internacional de Estados (ARENDT, 1989, p. 300-301). Caracteriza-se, portanto, normativamente o conceito de direito de asilo, proveniente de uma das vertentes do Direito Internacional de Proteção da Pessoa Humana (TRINDADE, 1997, p. 270-271), ou seja, no contexto do direito internacional dos refugiados, enquanto o direito a ter os seus direitos humanos garantidos, enquanto a instância que garantiria essa condição, visto que seu Estado de origem não conseguiu ou mesmo perpetua a perseguição contra esses indivíduos.

O reconhecimento da condição de refugiado como direito de asilo seria, assim, qualificado por sua função instrumental enquanto mecanismo que permite o exercício de outros direitos, antes violados e inacessíveis (MONGE, 2012, p. 26). Sua natureza jurídica, contudo, seria de direito de personalidade, âmbito de proteção irrenunciável, intransmissível e irrevogável, derivado da urgência em se restaurar o rol protetivo devido a todo ser humano, coerente com a responsabilidade de estatal de proteger os Direitos Humanos de todas as pessoas que estiverem presentes em seu território (GODOY, 2011, p.63). Nesse sentido, se estaria falando da responsabilidade internacional para com a proteção de direitos humanos, a qual derivaria do direito de ter os seus direitos respeitados, o "direito a ter direitos", na expressão de Arendt (1989, p. 330), originado da personalidade de todo ser humano (RAMOS, 2004, p. 58).

Incluído neste direito estariam os casos em que, apesar de não haver as condições previstas na definição clássica de refúgio, estariam presentes as condições previstas na definição ampliada da Declaração de Cartagena de 1984. De uma outra maneira, a definição ampliada já se encontra presente de modo a efetivar tal proteção na medida em que países como Venezuela adotam mecanismos a fim de regular a permanência de pessoas, as quais não podem ou não querem se valer do amparo de seu país de origem por uma série de outras razões (GODOY, 2011, p. 63), e que não estão previstas na definição advinda do sistema ONU, tais como os fluxos de haitianos pela região, por exemplo.

Seria um instrumento protetivo derivado da condição pessoal de se estar refugiado temporariamente, de ter atravessado fronteiras nacionais para ter seus direitos humanos protegidos, pois the foram perpetradas graves e generalizadas violações do Estado; afastando-se concepções de que o refúgio 
seria um título concedido pelo Estado de acolhida, que por meio do reconhecimento tem na prática o poder de conceder ou não a condição de refugiado, dependendo da expressão jurídica de um contexto político interno arbitrário (SILVA, 2020). Essas interpretações normativas estariam equivocadas, pois claramente focam e empoderam o Estado e não o indivíduo, o qual permanece em sua posição precária de pobre acolhido, desumanizado, tendo em vista às benesses do Estado (REIS, 2004).

Dessa forma, com tal amplitude normativa instituída por Cartagena, um exemplo de esforço regional que atende o princípio da responsabilidade compartilhada, compreendida como a distribuição justa entre Estados dos custos e benefícios, de acolher refugiados em seu território, e da solidariedade internacional, seria possível buscar soluções inovadoras e duradouras para os deslocados forçados que atravessam territórios, para além das soluções já previstas pelo ACNUR na segunda metade do século XX (2006, p.139-140). Indo ao encontro das iniciativas preconizadas pela Declaração de Nova York de 2016 e o Pacto Global da ONU, de 2018, no sentido de novas iniciativas criativas.

Essas soluções duradouras inovadoras se conectariam, portanto, com as boas práticas e as soluções já advindas desde o Programa de Ação do México de 2004 para a região da América Latina, no contexto do Processo de Cartagena e que caberiam para os recentes fluxos venezuelanos. A implementação de programas de autossuficiência e de integração local nas chamadas cidades solidárias, particularmente os refugiados venezuelanos urbanos e que já possuíssem experiência de vida em regiões semelhantes, que pretendiam evitar o máximo possível os fluxos irregulares e os movimentos secundários

Para promover uma resposta humanitária a favor daqueles que requeiram e mereçam proteção internacional, em particular em matéria de saúde e educação, também facilitaria a geração de fontes de emprego e projetos produtivos, seria necessário propiciar o desenvolvimento fronteiriço através da consolidação da presença de instituições do Estado, e de investimentos e projetos concretos de apoio da comunidade internacional, em programas definidos como reassentamentos, cidades e fronteiras solidárias (ACNUR, 2015, p. 271-274). 
Revista Brasileira de História \& Ciências Sociais - RBHCS

Vol. 13 No 26, Janeiro - Junho de 2021

Ou seja, já não são suficientes simplesmente a repatriação segura, a integração local e os programas de reassentamento clássicos enquanto respostas únicas para os deslocamentos maciços forçados (ACNUR, 2006, p.129-132), tão sublinhados na segunda metade do século XX. Contar com o suporte e a apoio de organismos internacionais e a proteção jurídica internacional continua cada vez mais desafiador, exigindo ainda mais a colaboração intensiva de agências, um maior número de países de acolhida, assim como o estabelecimento de programas e projetos inovadores e criativos para proteção de refugiados ao longo do tempo.

As diretivas estabelecidas no processo de Cartagena, através da Declaração e do Plano de Ação do México de 2004 já pareciam apontar na direção do que seria estabelecido posteriormente pelas iniciativas globais da Organização das Nações Unidas, no que tange a alcançar iniciativas criativas para o problema dos deslocamentos forçados de refugiados.

Estas soluções duradouras girariam em torno de executar programas de sensibilização dirigidos à sociedade civil e população local para prevenir sentimentos adversos e todas as formas de discriminação local (o episódio na fronteira de Roraima e da Venezuela demonstra a necessidade disso). Procurar elaborar planos estratégicos regionais de modo a suprir as necessidades básicas de proteção com um enfoque territorial e diferenciado no sentido de promover o desenvolvimento social e econômico, beneficiando por igual as pessoas que requerem proteção internacional e as populações locais de acolhida. Assim como considerar o perfil específico da população deslocada e a população das comunidades locais que habitam zonas e regiões fronteiriças. Do mesmo modo que considerar necessidades específicas de proteção de mulheres e homens, de minorias étnicas e de pessoas com deficiências, no contexto do fluxo venezuelano, por exemplo (ACNUR, 2015, p.272-276).

Tais iniciativas baseadas na solidariedade somente poderiam ser mantidas em um contexto de trabalho de cooperação ativa entre Estados de acolhida, a sociedade civil organizada e os organismos internacionais, tais como o ACNUR ou a OIM (Organização Internacional das Migrações). Essa linha de raciocínio também seria exposta posteriormente pelo Pacto Global da ONU de 2018, com contribuições financeiras da comunidade internacional, caracterizada pelo princípio da responsabilidade compartilhada. Nesse sentido, 
a iniciativa regional do processo de Cartagena já sublinhava a importância de assegurar a participação da sociedade civil nos mecanismos estabelecidos para garantir o marco de proteção das pessoas afetadas, particularmente em zonas fronteiriças e analisar a questão do deslocamento forçado de refugiados.

No âmbito das Américas, as iniciativas normativas do processo de Cartagena também previam um programa de reassentamento solidário, replicando as antigas propostas da ONU em aumentar o número de países de reassentamento (a terceira solução duradoura pregada pelo ACNUR).

A iniciativa brasileira para os venezuelanos, conhecida desde 2018 como Operação Acolhida, com a participação da sociedade civil organizada, do governo federal e da comunidade internacional, em operações tripartite, parece estar dentro deste espírito de Cartagena e da própria iniciativa global da ONU de 2018, pelo menos aparentemente.

Em meados de 2018, o governo federal brasileiro, através das Forças Armadas criou uma espécie de Força-Tarefa Logística Humanitária para o estado de Roraima, a atuação de recepção de venezuelanos, através do ordenamento da fronteira, abrigamento e interiorização dos migrantes. A missão seria cooperar com o governo federal acolhendo os imigrantes vulneráveis, através do apoio logístico, alimentação, saúde, suporte para o processo de interiorização, identificação e imunização, além da construção e ampliação de abrigos (ZANONI, 2019, p.138).

No entanto, esta iniciativa brasileira, ao deliberar que o Exército estabelecesse esta força tarefa para o estado federado de Roraima e a comandasse, tende a evidenciar que o fluxo migratório venezuelano seria encarado antes de mais nada como uma questão de segurança nacional. Ainda que caibam várias críticas, sobretudo os problemas de execução relativos a falta de coordenação e comunicação entre as entidades federadas brasileiras envolvidas com a Operação, não é surpreendente que essas iniciativas tendem a estar conforme o Espírito de Cartagena, no que tange a ser encaradas como boas práticas, e criativas para o acolhimento de migrantes e refugiados.

A Operação Acolhida teve início em 2018 com a junção de esforços em distintos níveis (político, estratégico, operacional e tático) de pessoas, autoridades, entidades religiosas, agências e organizações internacionais como o ACNUR, a OIM, o Conselho Norueguês para Refugiados (CNR), o UNICEF, o 
Revista Brasileira de História \& Ciências Sociais - RBHCS

Vol. 13 No 26, Janeiro - Junho de 2021

Fundo de População das Nações Unidas (UNFPA), organizações nãogovernamentais de ajuda humanitária, como o IMDH, a Fraternidade Federação Humanitária Internacional e Fraternidade Sem Fronteiras. (ZANONI, 2019, p. 138-139).

Desde então, esta atuação brasileira interiorizou vários venezuelanos nos diferentes estados-membros da federação brasileira. Conforme estatísticas oficiais da OIM foram interiorizados mais de dez mil venezuelanos 5 , em mais de 189 municípios brasileiros, distribuídos entre os estados do Amazonas, Bahia , Distrito Federal , Goiás , Mato Grosso, Mato Grosso do Sul, Minas Gerais, Paraíba , Paraná , Pernambuco , Rio de Janeiro , Rio Grande do Norte , Rio Grande do Sul, Rondônia , Santa Catarina , São Paulo, Sergipe , Alagoas , Ceará , Maranhão, Pará, Acre, Tocantins e Espírito Santo (OIM, 2019).

Destaca-se, ainda, o movimento secundário de venezuelanos em busca de familiares ou pela expectativa de reconstruir suas vidas. Todavia, se por um lado, a interiorização busca mitigar as tensões locais, evitando a concentração de imigrantes tanto na faixa de fronteira como na cidade de Boa Vista, por outro, ela esbarra na morosidade, em virtude da pequena disponibilidade de municípios brasileiros para recepcioná-los, uma vez que o principal obstáculo é a inserção dos venezuelanos no mercado de trabalho, fator essencial para lhes assegurar a autonomia econômica (ZANONI, 2019, p. 145).

Com todas as críticas pertinentes, em torno de melhorias no investimento de recursos econômicos, coordenação e comunicação entre os atores envolvidos (particularmente envolvimento maior dos municípios e governos locais para o recebimento e integração dos venezuelanos) tal operação parece ir ao encontro das boas práticas e das soluções duradouras previstas desde o Plano de Ação e a Declaração do México de 2004, no âmbito das fronteiras solidárias e cidades solidárias, renovadas no Brasil 2014.

Pois, se a Venezuela decidiu por não incorporar em sua legislação a definição ampliada de refugiados, é exatamente desta, agora, que seus nacionais precisam e buscam nos demais países da América Latina, incluindo a Colômbia e o Brasil, uma proteção referendada pelo ACNUR em sua Nota de Orientação

\footnotetext{
5 De acordo com dados apresentados pela OIM (2019) em seu Relatório de Deslocamentos Assistidos de Venezuelanos de abril de 2018 até dezembro de 2019 haviam sido interiorizados 27.222 imigrantes venezuelanos.
} 
Sobre Considerações De Proteção Internacional para os Venezuelanos, de maio de 2019:

Para os Estados que incorporaram a definição de refugiado contida na Declaração de Cartagena em sua legislação nacional, ou para os Estados que aplicam essa definição na prática, em observância às diretrizes da Corte Interamericana de Direitos Humanos, o ACNUR considera que a maioria das pessoas com nacionalidade venezuelana, ou pessoas apátridas que eram residentes habituais na Venezuela, possuem necessidade de proteção internacional conforme os critérios contidos na Declaração de Cartagena, baseado nas ameaças à sua vida, segurança ou liberdade resultante de eventos que atualmente estão perturbando gravemente a ordem pública na Venezuela. ${ }^{6}$

A referida orientação técnica considera a exceção prevista nas Diretrizes sobre Proteção Internacional $n^{0} 12$, do ACNUR, documento que prevê que em detrimento da recomendação de que em regra deve se aplicar a definição tradicional de refugiado, e em casos específicos deve-se permitir a aplicação das definições regionais, como da Declaração de Cartagena: "Sin embargo, la aplicación de las definiciones regionales sería más práctica y eficiente en situaciones de grupo o en contextos regionales específicos, siempre y cuando se apliquen las normas de tratamiento de la Convención de 1951"7.

É indicado, portanto, o uso do conceito mais abrangente ou que ofereça mais garantias, o qual abarcaria todas as demais situações relativas ao deslocamento forçado - ocasionado pela inviabilidade de permanecer em seu território e expressamente distinta da migração voluntária e não considerando também a alegação de direito ao desenvolvimento, visto que nas concepções de violação grave e generalizada de direitos humanos estão contidas todas as outras definições possíveis para o refúgio, inclusive dos documentos da ONU e da Unidade Africana.

Deste modo, a definição ou o conceito de refugiado recomendável para sua utilização na região é o que, além de conter os elementos da Convenção de 1951 e do Protocolo de 1967, considere também como refugiados as pessoas que

\footnotetext{
${ }^{6}$ ACNUR. Nota de orientação sobre considerações de proteção internacional para os venezuelanos: atualização I. 2019, p. 2. Disponível em: https://www.acnur.org/portugues/wpcontent/uploads/2019/05/Atualizac\%CC\%A7a\%CC\%830-Guidance-Note.pdf Acesso em: 12 jul 2019.

7 ACNUR, Diretrizes sobre Proteção Internacional no 12: Solicitações da condição de refugiado relacionadas com situações de conflito armado e violência sob o artigo $1^{\text {a }}(2)$ da Convenção de 1951 e/ou o Protocolo de 1967 sobre o Estatuto dos Refugiados e as definições regionais de refugiado, 2 de dezembro de 2016, HCR/GIP/16/12, https://www.refworld.org.es/docid/58c654244.html, parágrafos 86-88.
} 
tenham fugido dos seus países porque a sua vida, segurança ou liberdade tenham sido ameaçadas pela violência generalizada, a agressão estrangeira, os conflitos internos, a violação maciça dos direitos humanos ou outras circunstâncias que tenham perturbado gravemente a ordem pública. ${ }^{8}$

Fora disso, não se pode deixar de evidenciar o empenho regional histórico produzido em busca de estabelecer respostas para as migrações forçadas, por meio do Processo de Cartagena: “El arraigado compromiso de ofrecer protección a los que huyen em busca de seguridad es algo inherente a los valores de Latinoamérica y el Caribe. Existe una sólida y gran tradición de apertura, solidaridad y humanitarismo.” (GRANDI, 2017, p.4). Contudo, o cenário presente e as estimativas futuras não são otimistas, evidenciando o quanto falta para estabelecer a efetivação dos mecanismos regionais de proteção e possíveis soluções propostas que já existem no mundo normativo. Nesse contexto, o caso venezuelano é emblemático, e as iniciativas de boas práticas e de solidariedade compartilhada ainda são pequenas.

\section{CONCLUSÃO}

Pode-se estabelecer algumas conclusões que tendem a auxiliar na compreensão da interpretação do Processo de Cartagena, iniciado com a Declaração de Cartagena de 1984, à situação do fluxo migratório venezuelano. Um processo normativo construído no sentido de tornar efetivo as ações e iniciativas da região das Américas para a proteção internacional dos refugiados e de modo cooperativo, de modo que os países que apresentem menor fluxo de refugiados, combinado com legislações mais avançadas em termos protetivos, possam auxiliar os países com maior fluxo e um histórico de restrições de regulamentação.

Além disso, o auxílio financeiro e logístico necessários para lidar com a crise humanitária na Venezuela não deve alcançar somente a perspectiva regional, sendo essencial o apoio e a solidariedade da comunidade internacional em âmbito planetário nesse momento, conforme os compromissos de responsabilidade compartilhada, reafirmados por ocasião da Declaração de

8 Declaração de Cartagena de 1984, III, conclusão terceira. Disponível em https://www.acnur.org/fileadmin/Documentos/portugues/BD Legal/Instrumentos Internaci onais/Declaracao de Cartagena.pdf Acesso em: 11 jul 2019. 
Nova Iorque para Refugiados e Migrantes (2016) e o Pacto Global da ONU para Refugiados (2018).

Pode-se avançar que a crise humanitária venezuelana gera como produto um deslocamento internacional misto, composto por migração voluntária e, em grande parte por migração forçada, a qual, uma vez identificada pelos países de acolhida, deve ensejar uma imediata e ampla proteção, segundo as recomendações do ACNUR considerando que a condição de refugiado é personalíssima e um compromisso e dever dos Estados, decorrente diretamente da violação maciça de direitos humanos perpetrada contra o ser humano e derivada do direito internacional, e não uma concessão opcional advinda do direito interno, individual, dos Estados de acolhida.

Produzindo um deslocamento forçado tão significativo quanto o ocasionado pelo conflito armado na Síria, a crise humanitária venezuelana se equivale enquanto fator causador de migração forçada contemporânea. Portanto, analisando o caso concreto da Venezuela, evidencia-se que a definição ampliada de refugiado, estabelecida na Declaração de Cartagena de 1984, refina e coloca em perspectiva a necessidade de mudança na definição clássica, prevista na Convenção de Genebra de 1951, tendo em vista às transformações sociais e os fluxos migratórios mistos contemporâneos, combinados com os movimentos secundários.

Nesse sentido, compreende-se que a aplicação desta definição de refugiado da Declaração e do consequente Processo de Cartagena, ou seja, o processo regional iniciado com aquele documento em 1984, e renovado a cada dez anos, vem se mostrando como um instrumento não só extremamente útil, mas fundamental para o enfrentamento das atuais e futuras crises humanitárias de deslocamentos forçados na região, contribuindo para uma maior proteção dos direitos humanos das pessoas em movimento, as quais, sem poder contar com os governos de seus países de origem, acabam por buscar esse amparo na comunidade internacional.

Antes da criação de novas iniciativas normativas preconizadas pela Declaração de Nova York de 2016 e o Pacto Global de 2018, ambos no âmbito da ONU, para soluções duradouras enquanto medidas para o deslocamento forçado de refugiados, as iniciativas do Plano de Ação do México de 2004 no âmbito de Cartagena já apontavam tais soluções em torno de programas e 
planos estratégicos locais para atender necessidades básicas de proteção e distinto, com força para promover o desenvolvimento social e econômico em mão dupla: beneficiando migrantes e refugiados, assim como populações locais de recepção. O que caberia de forma emblemática para a situação dos fluxos venezuelanos em relação aos países vizinhos de acolhida.

Tais iniciativas baseadas na solidariedade e na cooperação só poderiam ser executadas e sustentadas em um contexto de trabalho de cooperação ativa entre Estados de acolhimento, a sociedade civil organizada e a comunidade internacional. A iniciativa brasileira em torno do surgimento da Operação Acolhida, com todos os problemas estruturais de execução que lhe caibam e de uma cultura política ainda voltada majoritariamente para a segurança nacional do Estado de acolhimento, parece um primeiro passo de boas práticas preconizadas pelo Espírito de Cartagena, iniciado ainda nos anos 80 do século passado.

\section{REFERÊNCIAS}

ACNUR. Situação Venezuela e respostas do ACNUR. Cartilha protegendo refugiados no brasil e no mundo. Disponível em: https://www.acnur.org/portugues/wp-content/uploads/2019/02/CARTILHAACNUR2019.pdf Acesso em: 24/03/ 2020.

ACNUR. ¿Quién es un refugiado? Disponível em: https://help.unhcr.org/venezuela/solicitando-la-condicion-de-refugiado/quienes-un-refugiado/ Acesso em: 10 jul 202ob.

ACNUR. Declaração de Cartagena de 1984. Disponível em https://www.acnur.org/fileadmin/Documentos/portugues/BD Legal/Instrume ntos Internacionais/Declaracao de Cartagena.pdf Acesso em: 11/07/ 2020.

ACNUR. Nota de orientação sobre considerações de proteção internacional para os venezuelanos: atualização I. 2019. Disponível em: https://www.acnur.org/portugues/wpcontent/uploads/2019/05/Atualizac\%CC\%A7a\%CC\%830-Guidance-Note.pdf Acesso em: 12/07/2020.

ACNUR. Diretrizes sobre Proteção Internacional $n^{0}$ 12: Solicitações da condição de refugiado relacionadas com situações de conflito armado e violência sob o artigo $1^{a}$ (2) da Convenção de 1951 e/ou o Protocolo de 1967 sobre o Estatuto dos Refugiados e as definições regionais de refugiado. 2016. Disponível em: https://www.refworld.org.es/docid/58c654244.html Acesso em: 12/07/ 2020. 
Revista Brasileira de História \& Ciências Sociais - RBHCS

Vol. 13 No 26, Janeiro - Junho de 2021

ACNUR. Relatório Tendências Globais 2019. Disponível em: https://www.unhcr.org/5ee200e37/\# ga=2.250861958.1675588954.16122238 49-343121451.1599159984 . Acesso em 22/10/2020.

ACNUR. Memórias do $3^{\circ}$ Aniversário da Declaração de Cartagena sobre Refugiados (1984-2014). Quito/Equador: ACNUR, 2015.

ACNUR. La Situación de los Refugiados en el Mundo Desplazamientos Humanos en el Nuevo Milenio. Barcelona: Icaria Editorial, 2006.

ANISTIA INTERNACIONAL. Informe 2017-2018: o estado dos direitos humanos no mundo. 2018. Disponível em: https://www.amnesty.org/download/Documents/POL1067002018BRAZILIAN \%20PORTUGUESE.PDF Acesso em: 12/07/2020.

ARENDT, Hannah. Origens do Totalitarismo. Tradução de Roberto Raposo. São Paulo: Companhia das Letras, 1989.

BRASIL. Ministério da Justiça e Segurança Pública. Estudo de país de origem: Venezuela. Nota Técnica n. ${ }^{0}$ 3/2019/CONARE_ Administrativo/CONARE/DEMIG/SEAJUS/MJ. 2019.

CARREÑO MALAVER, Ángela María, Refugiados colombianos en Venezuela: Quince años en búsqueda de protección. Memorias. Revista Digital de Historia y Arqueología desde el Caribe. 2014. Disponível em: http://www.redalyc.org/articulo.oa?id=85532557007 Acesso em: 13/07/ 2020.

DECLARAÇÃO AMERICANA DOS DIREITOS E DEVERES DO HOMEM. Aprovada na Nona Conferência Internacional Americana, Bogotá, 1948.

Disponível em: https://www.cidh.oas.org/basicos/portugues/b.Declaracao_Americana.htm Acesso em: 10/07/ 2020.

GABORIT, Maurício (org). Atrapados en la Tela de Araña - la migracion irregular de niñas y niños salvadorenhos hacia los Estados Unidos. El Salvador: Universidad Centroamericanas José Simeón Cañas, 2016.

GODOY, Gabriel Gualano de. O caso dos haitianos no Brasil e a via da proteção humanitária complementar. In. ACNUR. 60 anos de ACNUR: perspectivas de futuro. RAMOS, André de Carvalho; RODRIGUES, Gilberto; ALMEIDA, Guilherme Assis de (orgs.). São Paulo: Editora CL-A Cultural, 2011, p. 63.

GRANDI, Filippo. Prólogo: Solidaridad regional y compromisso com la protección em Latinoamérica y el Caribe. Revista Migraciones Forzadas, Latinoamérica y el Caribe: construyendo sobre uma tradición de protección. n. 56 p. $4-5,2017$.

HATHAWAY, James C. FOSTER, Michelle. The Law of Refugee Status. Cambridge: Cambridge University Press, 2014. 
HUMAN RIGHTS WATCH. Colombia: events of 2018. World Report 2019. Disponível em: https://www.hrw.org/world-report/2019/countrychapters/colombia Acesso em 10/07/2020.

INTERNATIONAL COMMITTEE OF THE RED CROSS. The humanitarian situation in Colombia worsened during 2018. Disponível em: https://www.icrc.org/en/document/humanitarian-situation-colombiaworsened-during-2018 . Acesso em: 10/07/2020.

JARDIM, Denise F. Imigrantes ou Refugiados? Tecnologias de controle e as fronteiras. Jundiaí: Paco Editorial, 2017.

LINDGREN ALVES, José Augusto. É Preciso Salvar os Direitos Humanos. São Paulo: Perspectiva, 2018.

MALAVER, Ángela M. C. Refugiados en las fronteras colombianas: Ecuador, Venezuela y Panamá. Revista Encrucijada Americana. Año 5. n. 1. 2012.

MENEZES, Fabiano de. O panorama da proteção dos refugiados na América Latina. In: 6o anos de ACNUR: perspectivas de futuro. RAMOS, André de Carvalho; RODRIGUES, Gilberto; ALMEIDA, Guilherme Assis de (orgs.). São Paulo: Editora CL-A Cultural, 2011.

MONGE, Federico M. El asilo como fundamento de la protección de los refugiados. In: LETTIERI, Martin (org.) Protección Internacional de Refugiados en el Sur de Sudamerica. Buenos Aires: Univerisidad Nacional de Lanús, 2012.

NORWEGIAN REFUGEE COUNCIL. Thousands of people newly displaced in Colombia. Disponível em: https://www.nrc.no/news/2019/april/thousands-of-people-newly-displacedin-colombia/ Acesso em: 10/07/2020.

OAU CONVENTION GOVERNING THE SPECIFIC ASPECTS OF REFUGEE PROBLEMS IN AFRICA. Adopted on 10 September 1969 by the Assembly of Heads of State and Government. CAB/LEG/24.3. It entered into force on 20 June 1974.

OEA. Informe preliminar sobre la crisis de migrantes y refugiados venezolanos en la región por el Grupo de Trabajo de la OEA. Washington, 2019.

OIM. Relatório de Movimentos Assistidos sobre a Estratégia de Interiorização dos Venezuelanos. junho de 2019. Disponível em: file://C:/Users/Joao\%2oLucas/Downloads/Informe\%2ode\%2ointerioriza\%C3 \%A7\%C3\%A3 o\%20-\%20Junho2019.pdf. Acesso em: 01/10/2020.

RESPONSE FOR VENEZUELANS. Coordination platform for refugees and migrants from Venezuela. Disponível em: https://r4v.info/es/situations/platform Acesso em: 13/07/2020. 
RESPONSE FOR VENEZUELANS. GIFMM Colombia: Venezuelan Refugees and Migrants - June 2019.

ROCHA, Rossana Reis (2004). Soberania, Direitos Humanos e Migrações Internacionais. Revista Brasileira de Ciências Sociais, v. 19, n. 55, jun, $\quad$ p. $150 . \quad$ Disponível http://www.scielo.br/pdf/rbcsoc/v19n55/aogv1955.pdf . Acesso em: 03/08/2020.

SÁEZ, Felipe Andrés Aliaga (org.). Migraciones Internacionales - alteridad y procesos sociopolíticos. Bogotá: Universidad Santo Tomás, 2017.

SILVA, Ádria Saviano Fabrício da. Da Acolhida á Diáspora: o caso Venezuela como Legitimador da Definição Ampliada de Refúgio Contida na Declaração de Cartagena de 1984. In: DA SILVA, César Augusto Silva (org.) Direito Internacional dos Refugiados: o processo de Cartagena de 1984. Belo Horizonte: Dialética, 2020.

TORRADO, Santiago. El éxodo venezolano atraviesa los Andes. El País. 2018. Disponível em: https://elpais.com/internacional/2018/08/17/actualidad/1534514057 453804 html Acesso em: 13/07/2020.

TORPEY, John. L'Invention du Passeport - Etáts, citoyenneté et surveillance. Paris: Belin, 2005.

TRINDADE, Antônio Augusto Cançado. Tratado de Direito Internacional dos Direitos Humanos. Vol.1. Porto Alegre: Sergio Fabris Editor, 1997.

VENEZUELA. Constitución De La República Bolivariana De Venezuela. Disponível em: https://www.oas.org/juridico/mla/sp/ven/sp ven-int-const.html Acesso em: 17/05/2020.

VENEZUELA. Ley Orgánica Sobre Refugiados O Refugiadas Y Asilados O Asiladas. 2001.

ZANONI, João Lucas. A Imigração Venezuelana para o Brasil: do ingresso em Pacaraima -RR ao início da interiorização em Dourados-MS. Dissertação (Mestrado), Universidade Federal da Grande Dourados - UFGD, Dourados, MS, 2019.

ZOLBERG, Aristide R. SUHRKE, Astri. AGUAYO, Sérgio. Escape from Violence - conflict and the refugee crisis in the developing world. New York: Oxford University Press, 1989. 